\title{
Correction to: Morphotectonic analysis of Sheer Khadd River basin using geo-spatial tools
}

\author{
Ankit Sharma $^{1} \cdot$ Prafull Singh $^{1} \cdot$ Praveen Kumar Rai $^{2}$
}

Published online: 2 May 2018

(C) Korean Spatial Information Society 2018

\section{Correction to: Spat. Inf. Res.}

\section{https://doi.org/10.1007/s41324-018-0185-z}

Unfortunately, Fig. 1 was published incorrectly in the online published article. The correct Fig. 1 is given in the following page.

The original article can be found online at https://doi.org/10.1007/s41324-018-0185-z.

Prafull Singh

psingh17@amity.ed; pks.jiwaji@gmail.com

1 Amity Institute of Geo-Informatics and Remote Sensing, Amity University, Sector 125, Noida 201303, India

2 Department of Geography, Institute of Science, Banaras Hindu University, Varanasi, India 


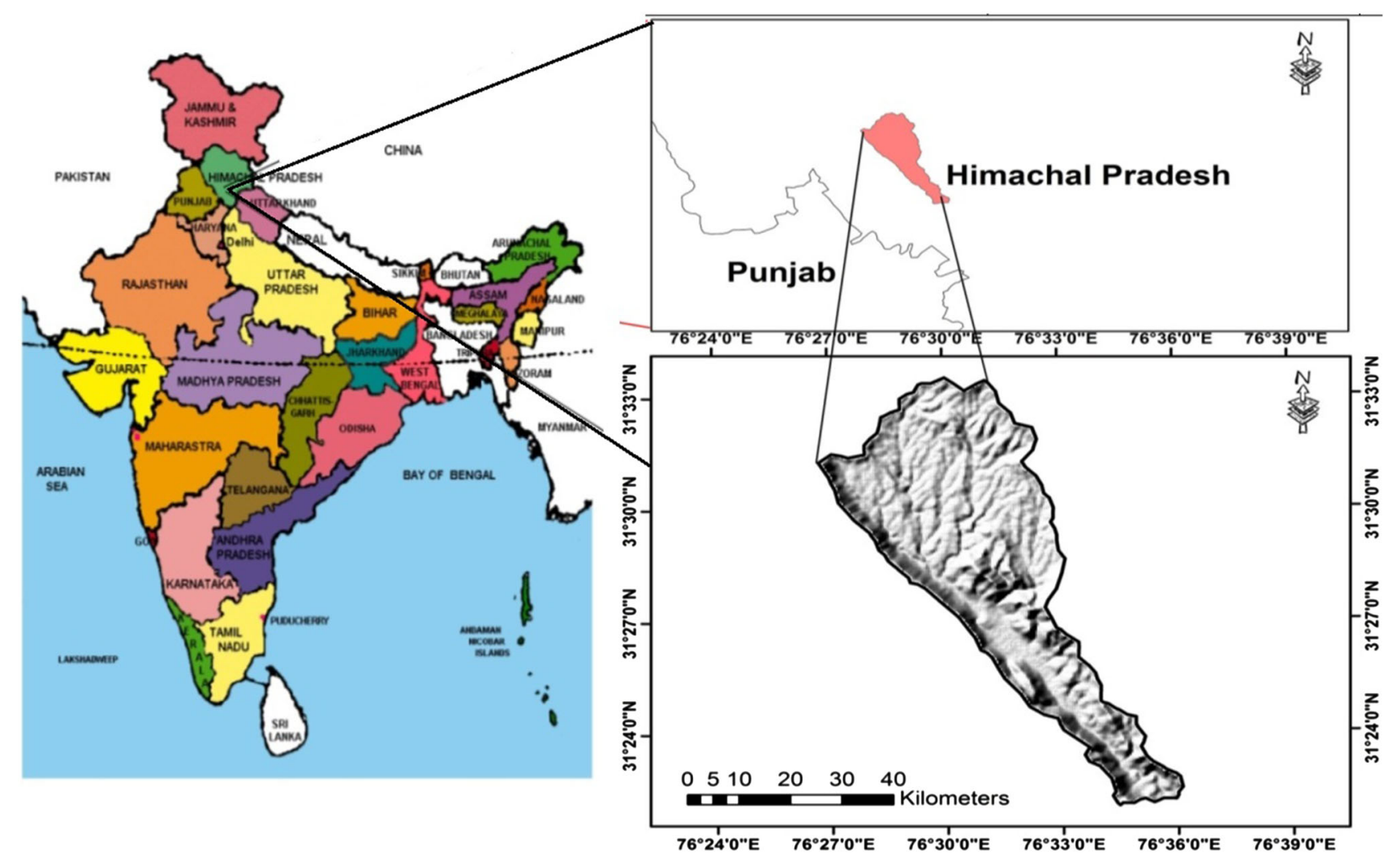

Fig. 1 Location map of the Sheer Khadd River basin 